\title{
PROGRESSION OF THE PHYSICAL ACTIVITY AFTER DELIVERY BY CAESAREAN SECTION
}

\author{
Nadezhda Popova, Georgi Petrov, \\ Daniela Mileshkina, Irina Nesheva
}

Key words: caesarean section, physiotherapeutic program, progression

\begin{abstract}
Summary
A number of Bulgarian women deliver by caesarean section for different reasons. After their discharge from the hospital there is no practice for giving detailed guidelines for physical activity after this type of birth. Aim: to offer adequate physiotherapeutic program after a cesarean delivery. Material and Methods. Physiotherapeutic program starts at 3rd postoperative weeks (POW) in the absence of contraindications and continues to up to 12th POW by gradually upgrading the exercises. It includes active exercises in the upper limbs with a gradual increase in elastic resistance, various kinds of squats, aerobic workout with different types of physical activity. Exercises for abdominal muscles begin after 6th POW in absence of contraindications. The type and dosage of the abdominal exercises are selected individually. The duration of the procedure do not exceed 45 minutes, which makes it suitable for every-day performance in this difficult period for daily organization. Conclusion. Physiotherapeutic program after a cesarean delivery is essential to the recovery process of the affected soft tissues from the surgical intervention. The individual selection of the exercises for the abdominal muscles and their application on the right time provides a good tone and positive emotional affection of the woman and also helps adaptation to her new social role.
\end{abstract}

The tendency to increase the deliveries by caesarean section (CS) is expressed. Therefore, there is a strong tendency for rise in the number of CS performed in Bulgaria. For example, at the largest obstetric and gynecological hospital in Bulgaria - "Maichin dom" - Sofia, in 1977, 4.1\% of all the deliveries were by caesarean section, in 1986.$13,92 \%$, in 2000.- 24.52\% (Димитров, 2003) and by the end of 2014.- 50\%. At national level, the trends are similar - in $201236 \%$ of the births were cesarean sections, 2013-38.4\%, and towards the end of 2014-41\% (Национален регистър на ражданията, 2014). After this type of delivery Physiotherapy (PT) might get start in the first days after the surgery, in which case the primary goal is early verticalization of the patients (Попов и кол., Kinser et al., 2012). Then, from the fifth postoperative day, until the third postoperative week, it is desirable for the patients to maintain a moderate level of physical activity, also avoid severe physical efforts and especially those causing pain and / or excessive fatigue. A therapeutic exercise program may include some basic exercises from supine lying position but the dosage should be individualized, as the comfort level of effort is the most important criterion. Breathing exercises are also suitable. They should be performed with an emphasis on diaphragmatic breathing but without retaining air also without pushing or resistive inhalation and/or exhalation.

Currently, after discharging from the hospital there is no practice of giving detailed guidance on the progression of physical activity. In the reviews of the available scientific and scholarly literature, PT after delivery by CS has not been well considered, especially in the later postoperative period. Nevertheless, authors agree that the physical activity after such an intervention assists the overall recovery process (Gursen et al, 2006; Wyrzykiewicz T. et al, 1979; Tsunechiro, 1976; Kinser et al., 2012), and in particular - improves the posture (Gursen et al., 2006), the scar elasticity (Sancho et al., Karakava et al, 2015; Stillermann, 2009; Kinser et al., 2012) and overall fitness of the patient. That is why the aim of our study is to offer an exemplary physiotherapeutic program for patients in the late postoperative period, after delivery by CS.

Material and methodology. The studied literature and mostly our practical experience shows that the active PT could start at the $3^{\text {rd }}$ postoperative week only in the absence of contraindications (postoper- 
ative complications, low levels of the hemoglobin, large amount of lochia, diastasis recti, etc.) and after a consult with an obstetrician-gynecologist. The total duration of our program is 12 postoperative weeks (POW).

Physical activity after the $3^{\text {rd }}$ to the end of the $4^{\text {th }}$ $P O W$. In this period the program consists active exercises with elastic resistance for the upper limbs also active exercises for the gluteal muscles, and closed kinetic chain exercises for the lower limbs. All exercises are performed in 2 sets of 10 repeti- tions at moderate pace as a circular workout. It is recommended to start with a resistance band TheraBand blue (its load corresponds to $2.6 \mathrm{~kg}$ weight). The duration of a session is $20-25 \mathrm{~min}$. The following sample exercises are appropriate:

1. The patient is sitting on a chair or on a Fitball, the shoulders are $90^{\circ}$ flexed, and she's holding the Thera Band. The TheraBand should be extended side wards but without increasing in lumbar spine while performing the exercise (Fig. 1A).

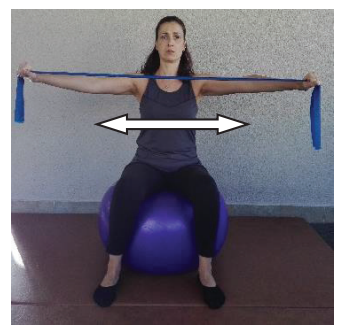

A

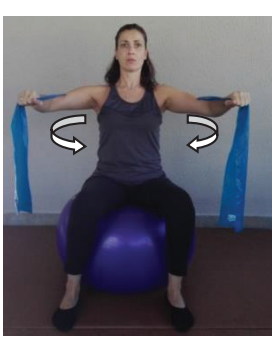

B

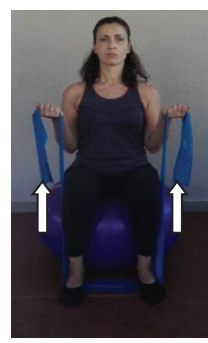

C

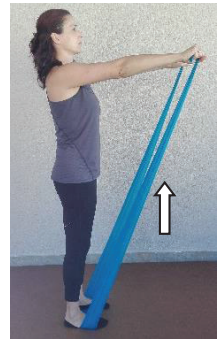

D

Fig. 1 (A-D). Upper limb exercises.

2. The patient is sitting on a chair or on a Fitball, the shoulders are $90^{\circ}$ abducted, the elbows are slightly flexed and the TheraBand passes behind the back. Shoulder transversal flexion is performed (Fig. 1B)

3. The patient is sitting on a chair or on a Fitball, the upper limbs are next to the body and the TheraBand passes under the feet. The patient performs flexion in the elbows. The movement should be performed only in the elbow joint without flexion in the shoulder or any extension of the body (Fig. 1C)

4. The patient is in standing position. The TheraBand passes under the feet, and each end is held by the respective hand. A shoulder flexion with extended elbows is performed. There should not be an increase of the lumbar lordosis during exercising. This is prevented by a slight contraction of the abdominal and gluteal muscles.

5. Spiral-diagonal patterns of motion - "drawing the sword" (Fig.2A), "replacing the sword" (Fig.2B), "reaching for seatbelt" (Fig. 2C), "strapping the seatbelt" (Fig.2D). The starting position is standing next to a suitable place for the elastic band. In each variant, the patient should maintain a good posture. Special attention should be paid to the correct scapulothoracic rhythm, the good spine position and the lack of rotation of the body.

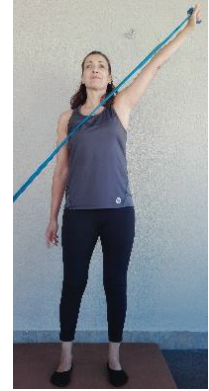

A

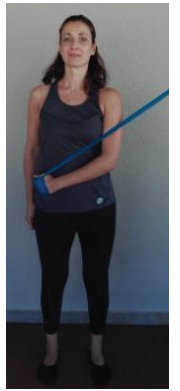

B

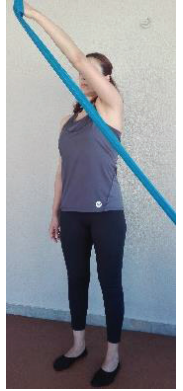

C

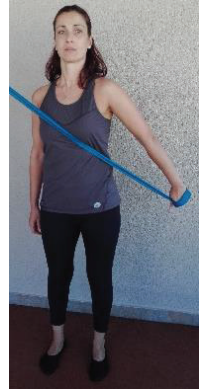

$\mathrm{D}$
Fig. 2 (A-D). Diagonal spiral patterns of motion

6. The patient is in supine lying position with flexed knees and feet on the floor. Pelvic lift is performed. There should not be an increase of the lumbar lordosis during exercising (Fig.3)

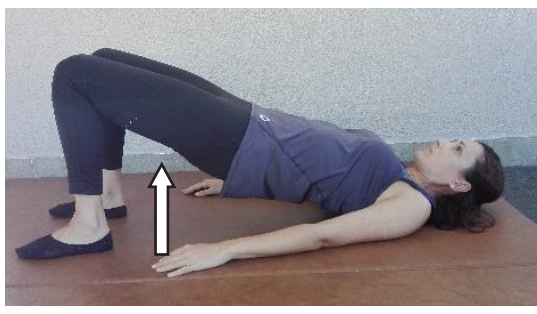

Fig. 3. Pelvic lift 
7. The patient is in side-standing position, next to a suitable location for tightening the TheraBand. The other end of the elastic band is bounded to the contralateral ankle. A hip abduction is performed in the physiological range of motion (Fig. 4A). 8. The patient is in side-straddle position, next to a suitable location for tightening the TheraBand. The other end of the strap is tied to the unilateral ankle. A hip adduction is performed until the exercised lower limb is brought next to the other (Fig.4B).

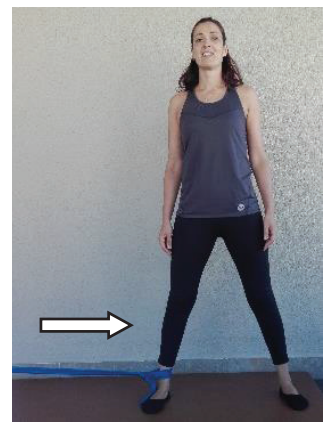

A

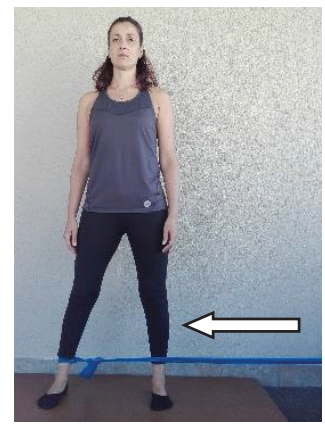

B
Fig. 4 (A-B). Hip abductors and adductors exercises.

9. The patient is in standing position with Fitball between her back and a wall. A squat is performed to a comfortable position, but no more than $90^{\circ}$ of knee and hip flexion (Fig. 5).

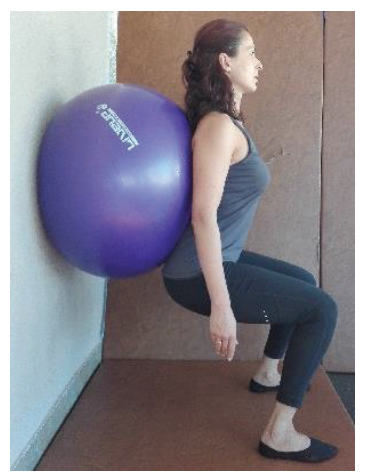

Fig. 5. Fitball squat

Another type of appropriate exercising for this period is walking. Our methodology offers daily walks of about 20-30 minutes. The pace of walking should be slow to moderate. If the walk is done with the baby stroller, the patient should pay attention on lifting the stroller to the curbs, stairs and other obstacles.

Physical activity after the $4^{\text {th }}$ to the end of the $6^{\text {th }}$ $P O W$. Exercises for the upper limbs remain the same, but after the $5^{\text {th }}$ POW the resistance may be increased with a black TheraBand (corresponds to $3.3 \mathrm{~kg}$ of free weight). The repetitions are also increased to 12 , the series remain two, on the principle of a circular workout. For lower limbs strengthening we add lunges with a dosage of 2 sets of 10 repetitions, for each leg (Fig.6).
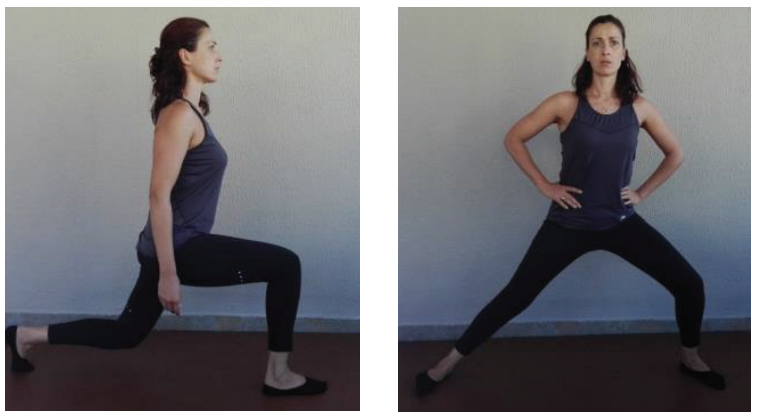

Fig. 6. Lunge Fig. 7. Side-lunge

The total duration of the procedure is $25-30 \mathrm{~min}$ utes. Walking also increases its duration to $30-40$ minutes, but the pace remains moderate.

Physical activity after the $6^{\text {th }}$ to the end of the $7^{\text {th }}$ $P O W$. At the end of the $6^{\text {th }} \mathrm{POW}$, in the absence of contraindication and good physical condition, exercises for activation of the abdominal muscles are included. A deep-diaphragmatic breathing with a tightening of the pelvic floor muscles is performed from the supine lying position with flexed knees and feet on the floor (Fig.8). There is a slow, full exhalation with the sound of "shush", "sss", "zzzz". The dosage for these exercises should be two sets of 5 repetitions.
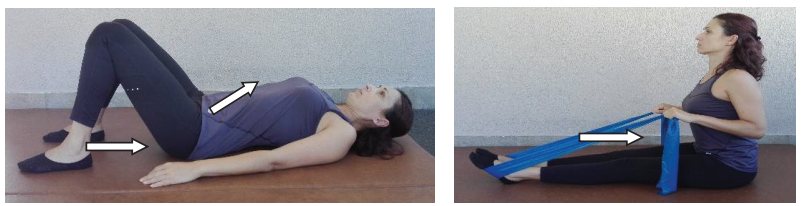

Fig. 8. Diaphragmatic breathing with Fig. 9. "Rowing exercise

pelvic floor contractions.

For the upper limb strengthening "the rowing" exercise is added. The patient is sitting on the floor with extended knees and feet in dorsal flexion. The TheraBand passes under the feet, the upper limbs are extended in elbows with a slight flexion in the shoulder. A stretch of the elastic band is performed as an imitation of a rowing movement (Fig.9). The dosage is 2 sets of 10 repetitions.

In the lower limb exercises we add a side lunge - 2 
sets of 10 repetitions, for each leg (Fig.7).

The total duration of the procedure is $30-35 \mathrm{~min}$.

The duration of the walks can be increased individually, depending on the patient's capacity, however it is good to take breaks every 30 to 40 minutes and without waiting for the accumulation of fatigue.

Physical activity after $7^{\text {th }}$ until the end of $8^{\text {th }} P O W$.
In this period the strengthening of abdominal muscles may happen with the following exercises:

1. Knee plank (Fig. 10A) -3 sets for $10 \mathrm{sec}$ holding the position.

2. Side knee-plank (Fig. 10B) - 3 sets for 10 sec holding the position for each side. In a good functional state, the upper limb may be extended in the knee (Fig.10C).

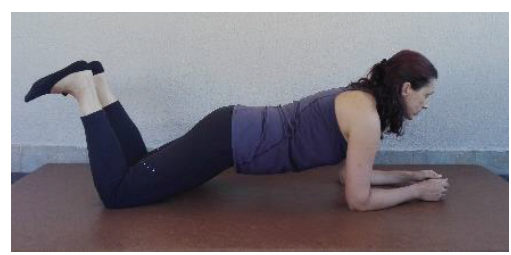

A

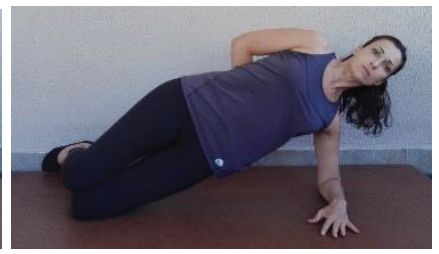

B

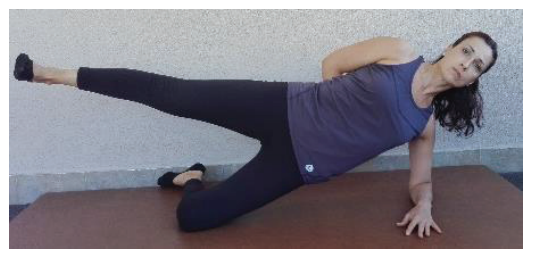

C

Fig. 10 (A-C). Different variations of a knee plank

3. Anti-rotational exercise for the body. The patient is in a side-standing position, next to a suitable location for tightening the TheraBand. The elastic band is attached to the wall at the level of the waist. The patient pulls the band ahead, with the shoulders in $80^{\circ}$ flexion and very slightly flexed elbows in front of the body (Fig. 11). In this position, when the arms are tight, the lateral pull of the elastic band "tries" to twist the torso to which the patient counters with isometric contraction of the abdominal musculature. There should be no tension or compression feeling in the low back (it occurs with increased lordosis and low contraction of the abdominal muscles.) Dosage -3 sets per 10 seconds on each side.

4. The starting position is as in Exercise 3. In this case the purpose of the exercise rotating the body on the outer leg, which plays the role of a pivot. For positive appliance, the heel of the inner leg is lifted in order to rotate the foot in the direction of the torso and pelvis Fig.12. The connection and position between the torso and the inner leg should not be disturbed. This is done by contraction of the oblique abdominal musculature. The dosage is $2 \mathrm{se}$ ries of 10 replicates.

The different types of squats and lunges are made in 3 sets of 10 reps.

The total duration of the procedure is $35-45$ minutes.
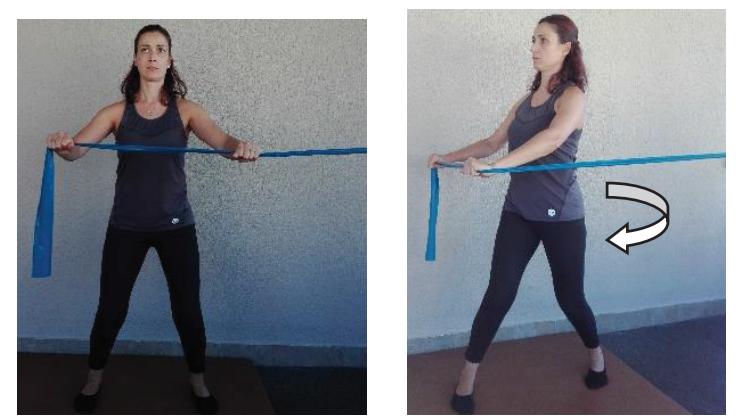

Fig. 11. Anti-rotational exercise for the body Fig.12. Pivoting over the outer leg

Walking is done with the patient's tolerance, but not less than 30-40 minutes a day.

Physical activity after the $8^{\text {th }}$ to the end of the 12th $P O W$. In the end of the $8^{\text {th }}$ to the end of the $9^{\text {th }}$ POW planks are upgraded to their "classic" performance (Fig. $13 \mathrm{~A}-\mathrm{B}$ ). The dosage is 3 sets held for 10 seconds for each plank.
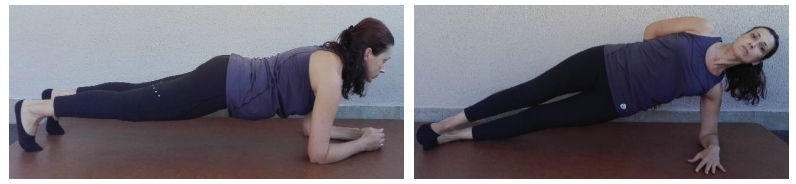

Fig. 13A. Plank Fig. 13B. Side-plank

The exercise "elastic deadlift" is added (Fig.14). The patient is standing with slightly flexed knees, the upper part of the body is tilted forwards, with flexion in the hips and spine in neutral. The TheraBand 
passes under the feet. The hands hold the two ends of the elastic band. The patient then performs simultaneously extension of the knees and hips, which straightens-up the upper part of the body against the resistance of theelastic band. The drive comes from the hamstrings and quads, while the spine muscles and abdominals keep the torso in neutral position. The dosage is 2 sets of 10 repetitions.

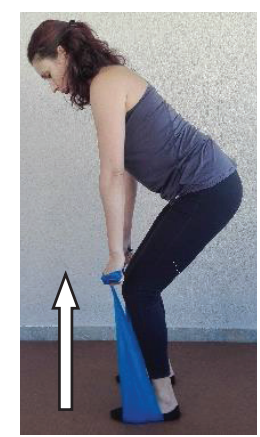

Fig. 14. Elastic deadlift

From $9^{\text {th }}$ to $10^{\text {th }}$ POW all of the exercises are done in 3 sets of 10 repetitions. The plank and side-plank holding should be increased to 20 to $30 \mathrm{sec}$.

As an aerobic workout some activities as cycling/ stationary bike (about $15-20 \mathrm{~min}$ to $30 \mathrm{~min}$ at the end of the period) and/or mountain trekking with overcoming a small altitude may be added.

From the $10^{\text {th }}$ to the $12^{\text {th }}$ POW the improved condition of the abdominal and back muscles allows more opportunities for education of correct performance of the daily activities - weight lifting, lifting of the baby, leaving it in a cot, etc.

At the end of $12^{\text {th }} \mathrm{POW}$, the total duration of the procedure is about $45-60$ minutes. During the entire period, aerobic workout activities remain the same - walking, cycling, mountain trekking. The dosage varies according to duration, intensity, altitude. After 12thPOW, swimmingorwateraerobicscanbeincluded at the discretion of the obstetrician-gynecologist. The distribution of the physical activity during the week is made in proportion to the physical shape and capacity of the patient. We recommend exercise sessions to be done 4 times a week, and the aerobic workouts two times a week. One day for full rest without the described activities is necessary.

The suggested progression of therapeutic exercises is appropriate for most women who had caesarian delivery.
Conclusions. The postpartum physiotherapeutic program is of utmost importance for the recovery process of the affected soft tissues from the surgical intervention. The individual selection of therapeutic exercises and the timely inclusion of abdominal muscles exercises provide good fitness and positive psycho-emotional effect on the woman. This also facilitates smoother adaptation in her new social role.

\section{References:}

Димитров А. (2003). Съвременни проблеми на абдоминалното родоразрешение. Дисертация за получаване на научнастепен: “Доктор на медицинските науки"

Информационна система за ражданията (2014), цитирана в http://www.ag-specialist.com/index.php

Попов Н. (2012). Въведение във физиотерапията основни средства и методи. София, НСА-прес, с. 290-302

Çıtak Karakaya İ, Yüksel İ, Akbayrak T, Demirtürk F, Karakaya MG, Ozyüncü Ö, Beksaç S. (2012). Effects of physiotherapy on pain and functional activities after cesarean delivery. Arch Gynecol Obstet.; 285(3), p. 621-7. doi: 10.1007/s00404-011-2037-0. PubMed PMID: 21830007.

Gürşen C, İnanoğlu D, Kaya S, Akbayrak T, Baltacı G. (2016). Effects of exercise and Kinesio taping on abdominal recovery in women with cesarean section: a pilot randomized controlled trial. Arch Gynecol Obstet.;293(3):557-65. doi: 10.1007/s00404-015-3862-3. PubMed PMID: 26329802.

Kinser, C., Colby, L. (2012). Therapeutic exercise. Foundations and techniques. Sixth edition. F. A. Davis Company, Philadelphia, p.952-954

Sancho MF, Pascoal AG, Mota P, Bø K. (2015). Abdominal exercises affect inter-rectus distance in postpartum women: a two-dimensional ultrasound study. Physiotherapy;101(3):286-91. doi: 10.1016/j.physio.2015.04.004. PubMed PMID: 26094117.

Stillerman E. C-section scar massage. (2009). Midwifery Today Int Midwife; (92):29, 64-5. PubMed PMID: 20092144.

Tsunechiro MA. (1976). Influence of physical and breathing exercise on intestinal evacuation in surgical postpartum patients. Rev Esc Enferm USP; (1):149-62. PubMed PMID: 1050051.

Wyrzykiewicz T, Kowalczyk J. (1979). Early exercise therapy after cesarean section and gynecological abdominal surgery. Ginekol Pol. 50(11):981-4. Polish. PubMed PMID: 544359.

\section{Contact information with the corresponding author}

Assistant professor Nadezhda Popova, $\mathrm{PhD}$

National Sports Academy "Vassil Levski"

Department "Theory and methodics of physiotherapy"

Studentski grad, 1700, Sofia, Bulgaria

Tel. +359 892299797

E-mail: popova nadia@abv.bg 